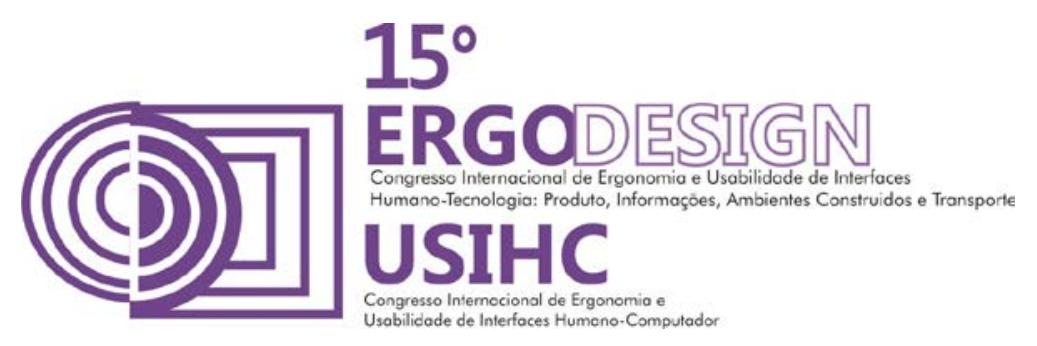

\title{
ANÁLISE ERGONÔMICA COM FOCO NA AVALIAÇÃO DAS CONDIÇÕES DE LEVANTAMENTO DE CARGA EM ATIVIDADES DE USINAGEM DA PRODUÇÃO DE BOMBAS SUBMERSAS
}

\section{ERGONOMIC ANALYSIS FOCUSING ON EVALUATION OF LOAD LIFTING CONDITIONS IN PROCESSING ACTIVITIES OF SUBMERGED PUMP PRODUCTION}

\author{
ANDRADE, Alexsandra Gomes (1); \\ ACIOLY, Angélica de Souza Galdino (2) \\ LOUZADA, Etiene Cerutti (3) \\ SOARES, Marcelo M. (4) \\ (1) Universidade Federal de Pernambuco, Especialista \\ e-mail: xandinhag@hotmail.com \\ (2) Universidade Federal da Paraíba/PPGDesign UFPE, Mestre \\ e-mail: angelica@ccae.ufpb.br \\ (3) Universidade Federal de Pernambuco, Especialista \\ e-mail: etiene@hotmail.com.br \\ (4) Universidade Federal de Pernambuco, Ph.D. \\ e-mail: marcelo2@nlink.com.br
}

\begin{abstract}
RESUMO
O artigo apresenta uma análise ergonômica de atividades de usinagem em uma indústria de produção de bombas submersas, mais especificamente, os resultados relacionados aos aspectos envolvidos no transporte e levantamento de cargas. A metodologia adotada foi a AET - Análise Ergonômica do Trabalho proposta por Anamaria de Moraes e Claúdia Mont'Alvão (2010), aplicandose as etapas iniciais de Apreciação e Diagnose Ergonômica. Entre os instrumentos utilizados estão: a equação de $\mathrm{NIOSH}$, Diagrama de Dores, dentre outros. O estudo se encerra com análise dos problemas prioritários e sugestões de melhoria.
\end{abstract}

Palavras-chave: Ergonomia; Indústria; Levantamento de Cargas.

\begin{abstract}
The paper presents an ergonomic analysis of machining activities in a submerged pumps production industry, more specifically the results related to the aspects involved in carrying and lifting loads. The methodology included AET - Work Ergonomic Analysis proposed by Anamaria de Moraes and Claudia Mont'Alvão (2010), applying the initial stages of assessment and diagnosis Ergonomic. Among the instruments used are: the NIOSH equation and diagram of Sorrows, among others. The study concludes with analysis of priority problems and suggestions for improvement.
\end{abstract}




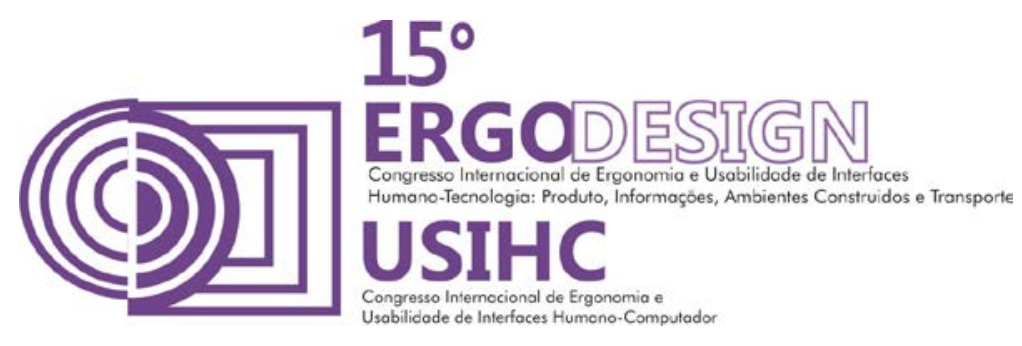

Key Words: Ergonomics; Industry; Lifting loads.

\section{INTRODUÇÃO}

Nos diversos aspectos relacionados ao trabalho, quais sejam, os aspectos comportamentais, ambientais e organizacionais, a atividade industrial representa um segmento importante para intervenções que visem a promoção da saúde e do bem estar dos seus trabalhadores. Sobretudo, porque a atividade industrial geralmente apresenta diversos tipos de riscos ao mesmo tempo.

Em termos gerais, o trabalho repetitivo, ambientes insalubres, posturas e mobiliários inadequados, turnos e carga de trabalho mal distribuídos, dentre outros problemas, são algumas características comuns do trabalho desenvolvido na atividade industrial. $O$ que resulta, comumente, em acidentes, constrangimentos posturais e/ou doenças ocupacionais. Assim, cada vez mais tem-se mostrado necessário um maior controle das variáveis envolvidas nas atividades industriais e consequentemente mais pesquisas aplicadas, a fim de eliminar ou amenizar seus efeitos negativos.

No que se refere ao levantamento de cargas no trabalho, a manipulação e transporte de cargas são as principais causas de lesões nos trabalhadores, destacando-se as lombalgias, segundo dados da Previdência Social de 2012. E ainda, dentre os 50 códigos CID (Código Internacional de Doenças), as lombalgias figuram em terceiro lugar com maior incidência em doenças e acidentes de trabalho. (BRASIL, 2012)

Nestes termos, o objetivo deste trabalho é apresentar uma análise ergonômica da atividade de usinagem de uma indústria de produção de bombas submersas, com foco na avaliação das condições de transporte e deslocamento de cargas pelo operador de montagem.

\section{2.}

\section{PROCEDIMENTOS METODOLÓGICOS}

Para a realização desta análise foi adotada a Metodologia de Análise Ergonômica do Trabalho (AET) proposta por Anamaria de Moraes e Claúdia Mont'Alvão (2010), que possibilita, através do ponto de vista da atividade, compreender e correlacionar os determinantes das situações de trabalho com as consequências para os trabalhadores e para o sistema de produção. Este artigo apresenta parte desta AET - a análise da postura e condições de levantamento de carga do operador do posto de trabalho de usinagem de uma indústria de montagem de bombas submersas.

Para tanto, a análise foi realizada cumprindo as seguintes etapas:

- Apreciação ergonômica - que é fase exploratória, na qual foram realizadas visitas à fábrica. Foram realizados registros fotográficos e em vídeo, visando a compreensão da rotina de trabalho e o mapeamento dos problemas ergonômicos;

- Diagnose ergonômica - fase seguinte, na qual permite aprofundar a investigação dos problemas identificados. Para o desenvolvimento desta fase foram utilizados os seguintes procedimentos/ferramentas:

1- Registro fotográfico e dos movimentos 


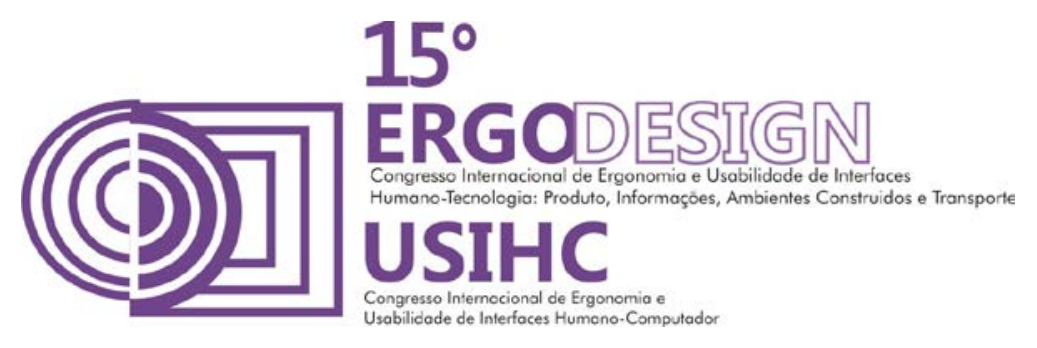

2- Entrevista estruturada com o funcionário do setor a fim de levantar as principais queixas nos últimos 30 dias, 12 meses e os afastamentos, além da aplicação do Diagrama de Dores (CORLETT e MANENICA, 1980)

3- Elaboração dos Diagramas de fluxo de processo e de afinidades para a análise das tarefas e do layout; e

4- Cálculo do Limite de Peso Recomendado e Índice de Risco para Lombalgia no levantamento de cargas, segundo equação de NIOSH (1994).

\section{POSTURA, LEVANTAMENTO E TRANSPORTE DE CARGA}

Segundo Barreira (1989), a postura de trabalho é função das exigências físicas da tarefa, dos espaços de trabalho disponíveis, dos equipamentos e máquinas envolvidos e seus acionamentos de comando, distribuição temporal da tarefa, assim como o modo operatório adotado por cada indivíduo. No entanto, a inadaptação do posto de trabalho às capacidades e restrições físicas do trabalhador o faz adotar más posturas que podem levar a rápida fadiga muscular, dores, lesões e doenças osteomusculares crônicas, responsáveis pela maior parte dos afastamentos no ambiente laboral.

Apesar da importância que a postura possui no trabalho, um cenário comum na concepção dos postos de trabalho são consideradas apenas as necessidades da atividade, ficando as posturas a serem adotadas pelo trabalhador em segundo plano (BRASIL, 2001).

Quando relacionamos a postura assumidas em atividades de manuseio de cargas pesadas, percebe-se que, apesar dos avanços tecnológicos onde o manuseio já é realizado de forma mecanizada, ainda são comuns situações de trabalho que exigem o esforço físico do trabalhador para realização dessa tarefa.

No trabalho com manipulação de cargas existem situações impostas à coluna vertebral, que constituem as causas mais frequentes de lesões, como: esforço em flexão anterior, esforço excessivo e esforço inadequado (BARREIRA,1989).

A grande frequência de acidentes e lesões nessas situações de trabalho ocorrem por não ser respeitadas as capacidades físicas individuais, como também, os treinamentos insuficientes (IIDA, 2005).

A NR-17 (Norma Regulamentadora de Ergonomia), do Ministério do Trabalho e Emprego (MTE), já estabelece que todo trabalhador designado para esse tipo de atividade, deve receber treinamento ou instruções quanto aos métodos que deverá utilizar a fim de preservar sua saúde e prevenir acidentes.

No que se refere aos limites de carga, a supracitada norma, preconiza que o trabalhador não deve manusear carga cujo peso seja suscetível de comprometer sua saúde e segurança.

Para encontrar qual peso é recomendável para o trabalhador, a NR-17 baseia-se na equação desenvolvida pela National Institute for Occupational Safety and Health (NIOSH). Desenvolvida em 1981, revisada em 1991 e em 1994, a equação estabelece como valor de referência de $23 \mathrm{~kg}$, a uma altura de $75 \mathrm{~cm}$ do solo e a $25 \mathrm{~cm}$ de distância do corpo (BRASIL, 2002). 


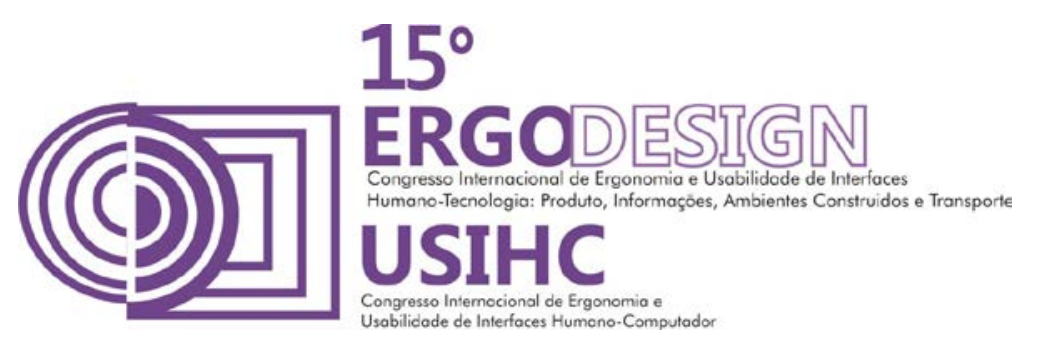

Caso a situação de trabalho analisada não atenda a essas condições, o Limite de Peso Recomendado (LPC) é calculado a partir da multiplicação do valores de referência por 6 fatores de redução, conforme equação abaixo descrita (WATERS et al, 1994):

$$
\mathrm{LPC}=23 \times \mathrm{HM} \times \mathrm{VM} \times \mathrm{DM} \times \mathrm{AM} \times \mathrm{FM} \times \mathrm{CM} \text { [Eq. 01] }
$$

O Valor constante fixado em $23 \mathrm{~kg}$ corresponde à carga que, em condições ideais, $75 \%$ das mulheres e $90 \%$ dos homens levantariam sem que a compressão discal supere os limites de segurança. Os fatores indicados na Equação 01 apresentada correspondem a:

- Fator Distância Horizontal (HM) - A compressão discal aumenta proporcionalmente a distância entre a carga e a coluna. $\mathrm{HM}=25 / \mathrm{H}$, onde $\mathrm{H}$ é a distância horizontal entre a projeção no solo do ponto médio entre as pegas e a projeção do ponto médio entre os tornozelos.

- Fator Altura (VM) - Distância vertical entre o ponto de pega e o solo. Determina-se: $\mathrm{VM}=(1-0,003|\mathrm{~V}-75|)$.

- Fator Assimetria (AM) - O movimento que começa e termina fora do plano médio sagital. $O$ ângulo de giro $(A)$ ao levantar ou depositar a carga deve ser medido. $A M=$ $1-(0,0032 \mathrm{~A})$

- Fator de Frequência (FM) - Definido pelo número de levantamentos por minuto, duração da tarefa e altura, conforme tabela abaixo:

- Fator de pega (CM) - Considera a facilidade da pega e altura vertical de em que se encontra a carga. Estudos mostram que a capacidade de levantamento fica diminuída por uma má pega.

Já a avaliação do risco de desenvolvimento de lombalgias para uma situação de trabalho, denominado Índice de Levantamento (IL) pode ser encontrado a partir da seguinte equação (WATERS et al, 1994):

$$
\text { IL = Peso da carga/LPC [Eq. 02] }
$$

Onde:

Quadro 01 - Estratificação do Risco segundo IL (BRASIL, 2002).

\begin{tabular}{|l|c|l|}
\hline Risco Limitado & IL<1 & $\begin{array}{l}\text { A maioria dos trabalhadores que realizam esta tarefa } \\
\text { não deveriam ter problemas }\end{array}$ \\
\hline $\begin{array}{l}\text { Aumento Moderado } \\
\text { de Risco }\end{array}$ & $\begin{array}{c}1<\mathrm{IL} \\
<3\end{array}$ & $\begin{array}{l}\text { Alguns trabalhadores podem adoecer. A tarefa deve } \\
\text { ser redesenhada ou atribuída a trabalhadores } \\
\text { selecionados }\end{array}$ \\
\hline $\begin{array}{l}\text { Aumento elevado de } \\
\text { Risco }\end{array}$ & IL>3 & $\begin{array}{l}\text { Inaceitável do ponto de vista ergonômico, deve ser } \\
\text { modificada. }\end{array}$ \\
\hline
\end{tabular}

Cabe salientar que, a equação de $\mathrm{NIOSH}$ foi concebida para avaliar o risco associado ao levantamento de carga e determinar um limite de peso adequado para que a tarefa possa 


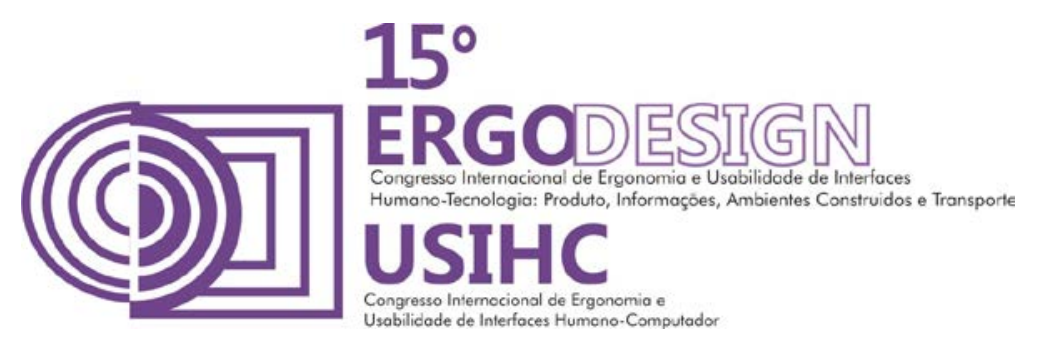

ser realizada sem riscos elevados para o desenvolvimento de lombalgias. A ferramenta, portanto, apresenta limitações, não devendo ser interpretada de forma errônea.

\section{APRECIAÇÃO ERGONÔMICA}

\subsection{A Unidade Produtiva}

A análise foi realizada numa pequena empresa, fundada no ano de 2000 , que produz e presta manutenção de bombas submersas. A empresa possui 11 funcionários, e em uma jornada de trabalho de 8 horas diárias, tem-se uma produção média de 100 bombas/dia. E dependendo da demanda, a produção pode chegar a 160 bombas/dia.

O produto produzido - a Bomba submersa - consiste numa bomba centrífuga acoplada a um motor elétrico capaz de funcionar submerso na água utilizada para drenar ou bombear água ou outros fluidos. É composta por peças moldadas em alumínio, plástico e borracha, cabos elétricos, fios esmaltados e resina química.

O processo de produção das bombas, em termos gerais se divide em 5 etapas: (1) Confecção da Bobina; (2) Preparação da Caneca; (3) Montagem do Corpo; (4) Preparação do Kit; e (5) Embalagem da Bomba.

Para a realização de cada processo a indústria possui os seguintes postos de trabalho: (PT 1) Confecção das bobinas/preparação dos kits do produto; (PT 2) Montagem e teste da caneca; (PT 3) Preparação da Resina química; (PT 4) Manutenção de bombas; (PT 5) Montagem final e embalagem da bomba; (PT 6) Teste final da bomba; (PT 7) Preparação da caneca e tornearia de peças.

Este artigo apresenta a AET da preparação da Caneca (Figura 01) - Processo 2 desenvolvido no posto de trabalho 7 (Preparação da caneca e Tornearia de peças) localizado no primeiro pavimento da unidade produtiva.
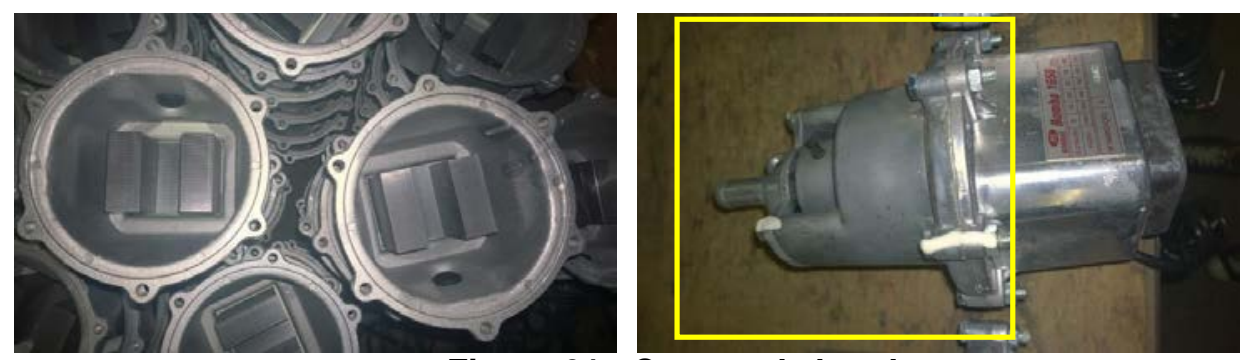

Figura 01 - Caneca da bomba

\subsection{Descrição e Análise da Tarefa}

Para o início da montagem das bombas submersas é necessária a preparação da "Caneca", que é a peça metálica que irá recepcionar o núcleo da bomba responsável por seu mecanismo elétrico. Essa preparação consiste em duas atividades: (1) jateamento processo no qual a peça é submetida a jatos abrasivos para receber acabamento asperizado, com o objetivo de melhorar a adesão da resina no momento da colagem das peças do núcleo; (2) perfuração da peça - perfuração serve para a saída do cabo de alimentação elétrica. As canecas são estocadas em sacos com 30 unidades, os quais possuem cerca de $12 \mathrm{Kg}$ cada. 


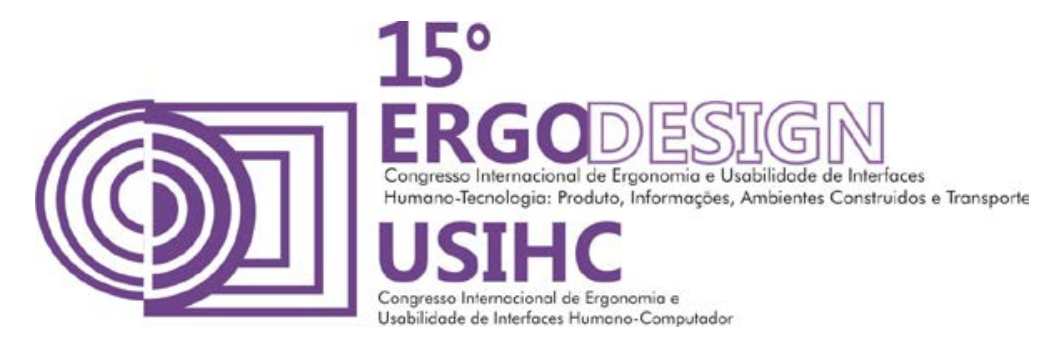

A atividade é realizada por um único operador, com 53 anos, $62 \mathrm{Kg}$, e 1,65 m de altura, 3 anos de empresa, sendo desses, menos de 1 ano na função citada. O posto de trabalho, localiza-se no pavimento superior onde também ficam estocados os suprimentos para a produção (Figura 02).

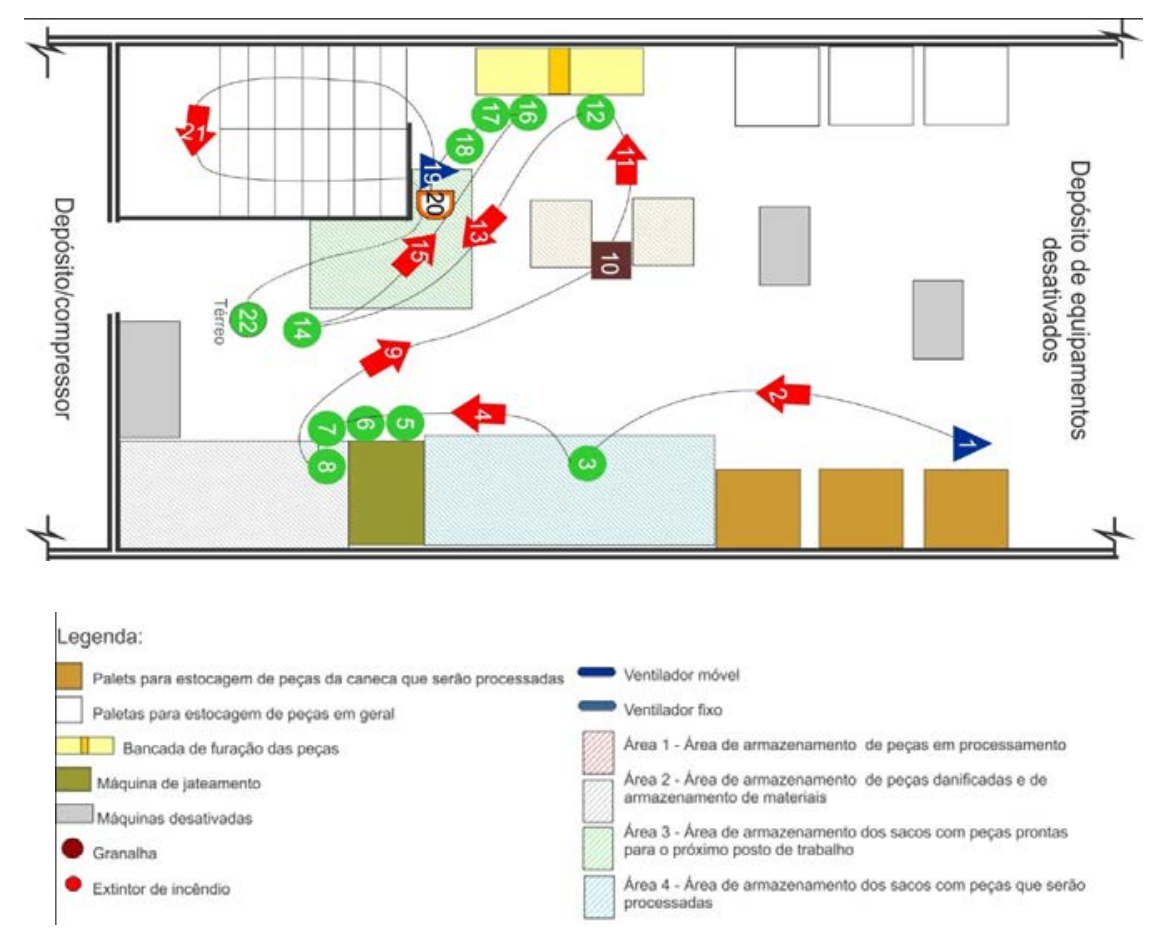

Figura 02 - Layout do PT 7/Mapofluxograma do processo de preparação e tornearia da caneca

O esquema a seguir demonstra a sequência das atividades do processo avaliado.

Quadro 02 - Jateamento das peças 

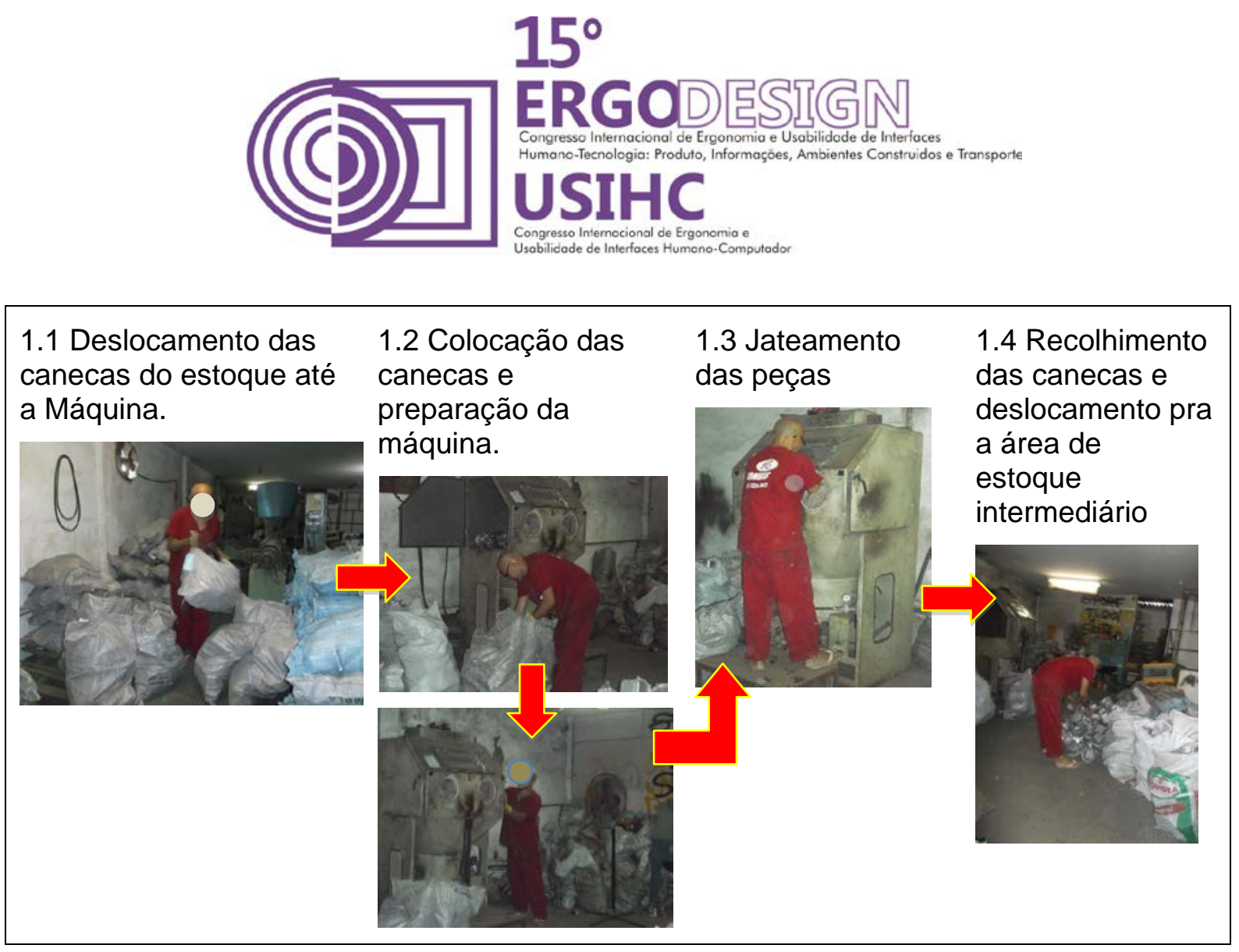

Quadro 03 - Perfuração das peças

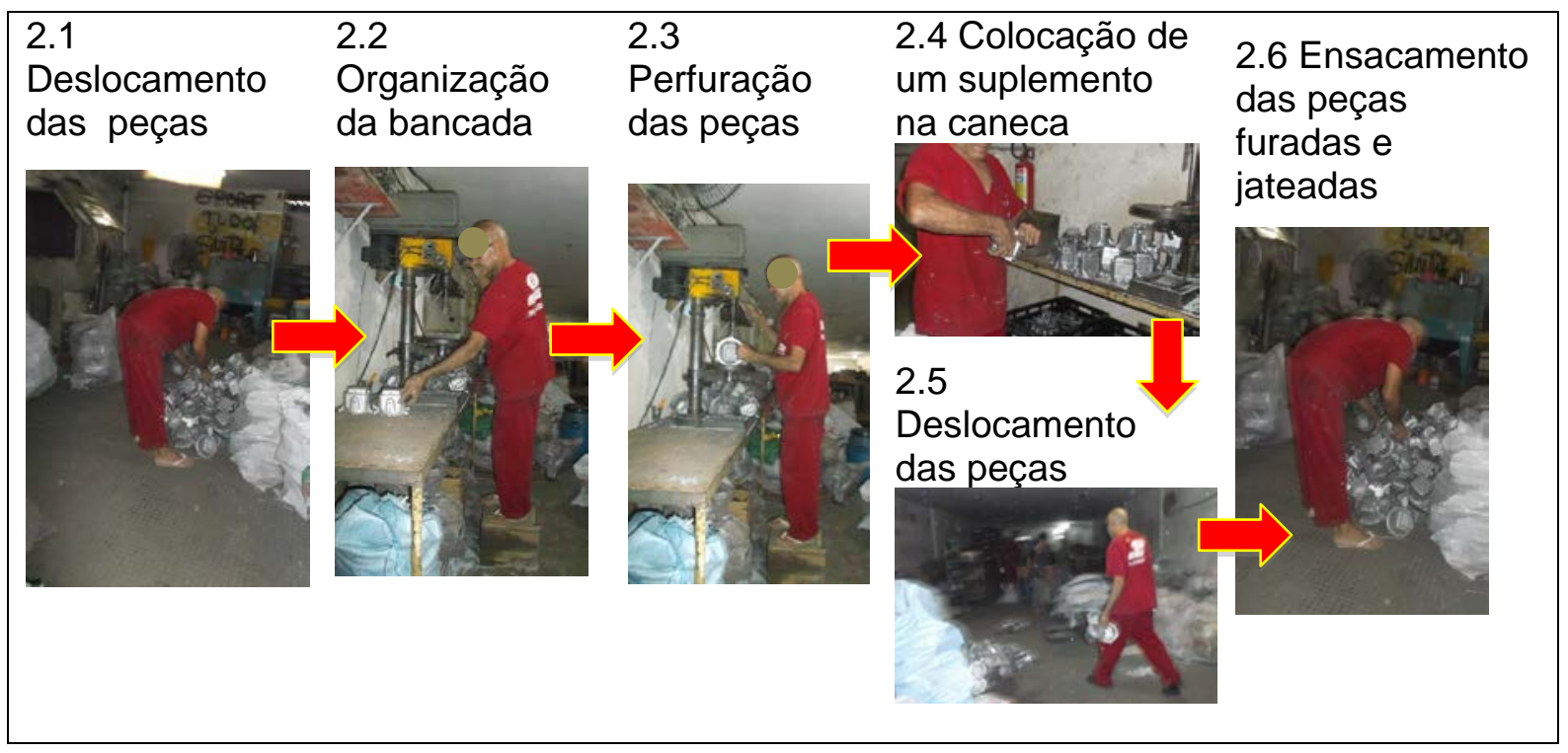

\subsection{Problematização}

Os problemas encontrados a partir da análise foram identificados, sistematizados e priorizados a partir da técnica de análise GUT. Assim tem-se a ordenação das prioridades para as ações serem implementadas, com base na Gravidade, Urgência e/ou Tendência que tais problemas possam apresentar, numa escala de 1 a 5 (quadro 04). 


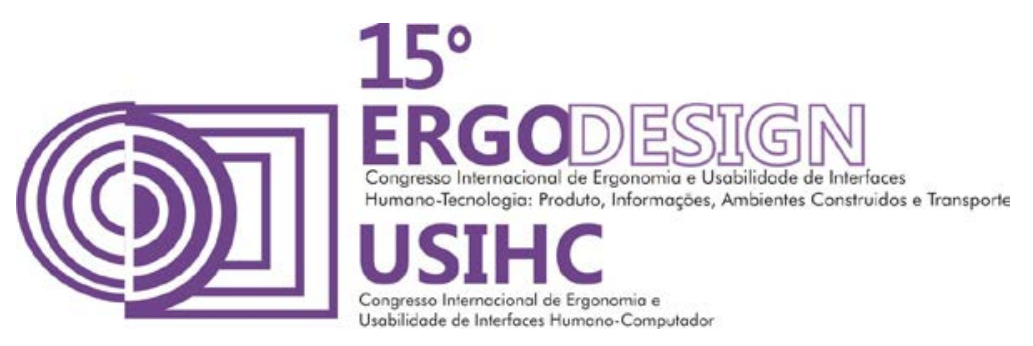

Quadro 04 - Priorização dos problemas segundo a análise GUT.

\begin{tabular}{|c|c|c|c|c|c|}
\hline PROBLEMAS & GRAVIDADE & URGÊNCIA & TENDÊNCIA & $\begin{array}{c}\text { Total } \\
(\mathrm{GxU \times T})\end{array}$ & Prioridade \\
\hline Posturais & 5 & 5 & 4 & 100 & $1^{\circ}$ \\
\hline Dimensionais & 3 & 3 & 3 & 27 & $5^{0}$ \\
\hline Acionais & 2 & 2 & 2 & 8 & $7^{\circ}$ \\
\hline Operacionais & 5 & 5 & 4 & 100 & $1^{\circ}$ \\
\hline Físico - ambientais & 2 & 3 & 2 & 12 & $6^{\circ}$ \\
\hline Químico - ambientais & 2 & 3 & 1 & 6 & $8^{\circ}$ \\
\hline Acidentários & 4 & 5 & 4 & 80 & $2^{\circ}$ \\
\hline Arquiteturais & 4 & 4 & 4 & 64 & $3^{\circ}$ \\
\hline Organizacionais & 3 & 4 & 3 & 36 & $4^{\circ}$ \\
\hline
\end{tabular}

O quadro apresenta os problemas prioritários encontrados, sendo os mesmos causados pelos seguintes aspectos:

- Os problemas posturais são relacionados à necessidade do operador pegar os insumos da produção a partir do local de armazenamento no chão, ou seja, o levantamento e deslocamento manual de carga, ocasionando o movimento repetitivo de flexão anterior extrema da coluna;

- Os problemas operacionais são relacionados sobretudo decorrente ao atual layout do posto de trabalho que não prioriza o fluxo racional e ordenado das tarefas, e ainda pela falta de equipamentos de transporte e apoio para as peças, obrigando operador a fazer deslocamentos e carregamento de peso repetitivos e desnecessários;

- Os problemas acidentários são relacionados à não utilização de EPI e à falta de equipamentos que auxiliem a movimentação de materiais e carga;

- Os problemas arquiteturais são relacionados aos aspectos ambientais. Em termos gerais, o operador é exposto à alta temperatura, ruído intenso das máquinas e a iluminação é insuficiente. E ainda pela realização dos processos produtivos em pavimentos diferentes, onde o processo da preparação da caneca ocorre no pavimento superior, onde fica o estoque dos insumos para a produção. Desta forma, tem-se a necessidade de deslocamentos e carregamentos de carga para abastecer a produção nas etapas produtivas subsequentes.

\section{DIAGNOSE ERGONÔMICA}

\subsection{Cálculo do Limite de peso Recomendado (LPC)}

A avaliação das condições de levantamento de carga foi realizada por meio da equação desenvolvida pelo National Instituto for Occupational Safety and Health (NIOSH). A equação propõe a avaliação do levantamento de cargas a partir de variáveis como: peso do objeto manuseado, distância da carga em relação ao corpo, frequência de levantamento; tempo total do levantamento, possibilidade de preensão ou pega. A partir dessas condições é 


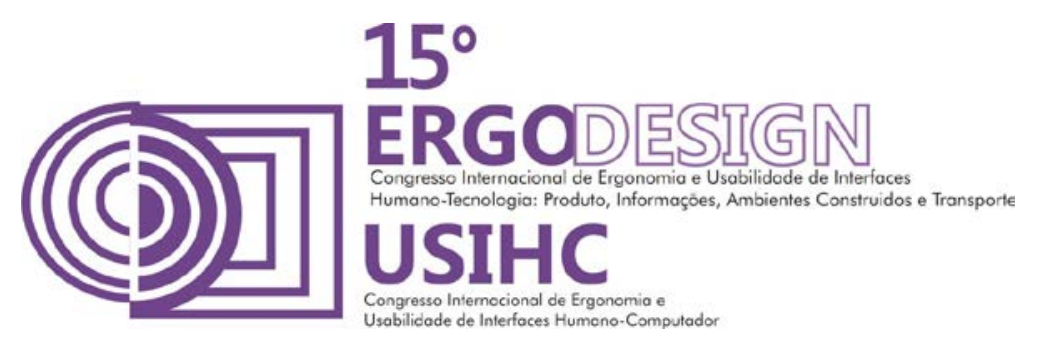

determinado o Limite de Peso Recomendado (LPC) para as características da tarefa realizada, bem como a avaliação do risco de desenvolvimento de lombalgias para a situação, denominado Índice de Levantamento (IL) segundo equações abaixo:

$$
\mathrm{LPC}=23 \times \mathrm{HM} \times \mathrm{VM} \times \mathrm{DM} \times \mathrm{AM} \times \mathrm{FM} \times \mathrm{CM} \quad \mathrm{IL}=\text { Peso da carga/LPC }
$$

No posto de trabalho analisado o levantamento de carga ocorre no início da tarefa, quando operador levanta os sacos da área de estoque e os carrega até a máquina de jateamento. Quando chega até a máquina, o operador eleva um pouco mais o saco a fim de virá-lo e despejar todas as canecas dentro da jateadora (Figuras 03 e 04).
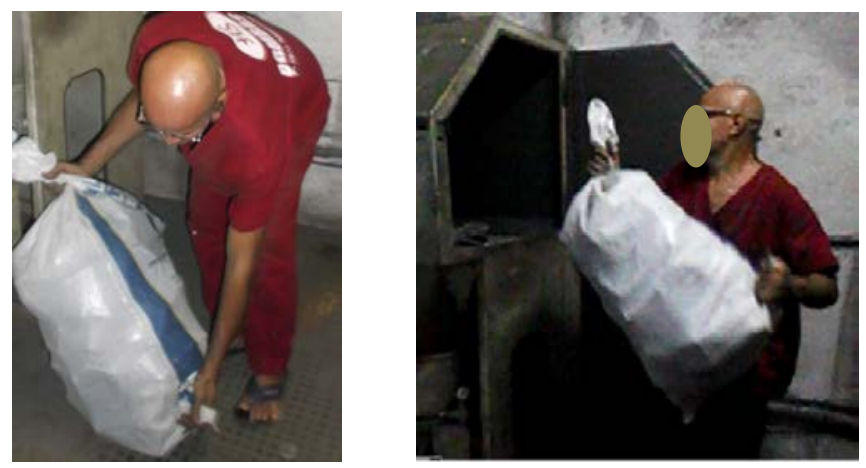

Figuras 03 e 04 - Levantamento do saco: início (a partir do chão) e destino da carga.

Considerando que, a equação NIOSH foi concebida para avaliar o vencimento da inércia da carga, ou seja, apenas onde há o levantamento propriamente dito, a mesma foi aplicada em três momentos: no início da atividade - quando é retirado o saco da área de estoque, nas situações quando a carga está depositada no chão (situação 1) e sobre paletes de $13 \mathrm{~cm}$ (situação 2); e no destino da carga - momento de nova elevação para alcançar a abertura da máquina jateamento (situação 3). Vale ressaltar que nos dias avaliados não havia cargas empilhadas.

A tarefa em análise não se caracteriza de forma expressiva pelo manuseio de carga. Conforme informação do operador a frequência de levantamento dos sacos varia, ocorrendo em média 8 sacos por dia, 4 no turno da manhã e os outros 4 no turno da tarde. O intervalo entre o levantamento de um saco e outro é o tempo do operador jatear as 30 peças contidas no saco, furá-las e colocá-las dentro do saco novamente, o que é variável, pois depende do ritmo adotado pelo trabalhador que também dependerá da demanda da produção do dia. Dessa forma consideramos uma frequência baixa de levantamento $(0,2 / \mathrm{min})$. Para os cálculos foram considerados as seguintes medidas:

Quadro 05 - Medidas das variáveis utilizadas para a equação NIOSH.

\begin{tabular}{|l|l|l|l|l|l|l|l|}
\hline & Carga $(\mathrm{Kg})$ & $\mathrm{H}(\mathrm{cm})$ & $\mathrm{V}(\mathrm{cm})$ & $\mathrm{D}(\mathrm{cm})$ & A (graus) & $\mathrm{F}($ Lev./min) & Pega \\
\hline Situação 1 & 12,6 & 48 & 0 & 90 & 0 & 0,2 & Má \\
\hline Situação 2 & 12,6 & 48 & 13 & 77 & 0 & 0,2 & Má \\
\hline
\end{tabular}




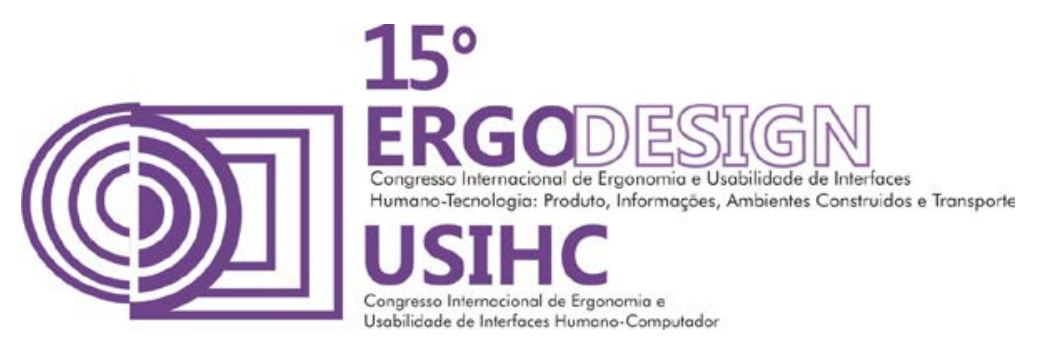

\begin{tabular}{|l|l|l|l|l|l|l|l|}
\hline Situação 3 & 12,6 & 50 & 90 & 30 & 45 & 0,2 & Má \\
\hline
\end{tabular}

A partir dos parâmetros estabelecidos foram encontrados os seguintes limites de peso recomendado e o risco da tarefa para cada etapa. Nota-se que para as características da tarefa executada o peso recomendado é inferior ao real, com uma diferença aproximada de $5 \mathrm{~kg}$.

Quadro 06 - Limite de peso recomendado e risco da tarefa.

\begin{tabular}{|l|l|l|}
\hline Etapa & Limite de peso recomendado & Risco da tarefa \\
\hline Tarefa 1 & 7,257 & $\mathrm{IL}=1,73-$ Risco Moderado \\
\hline Tarefa 2 & 7,710 & $\mathrm{IL}=1,63-$ Risco Moderado \\
\hline Tarefa 3 & 8,207 & $\mathrm{IL}=1,53-$ Risco Moderado \\
\hline
\end{tabular}

Os resultados encontrados implicam riscos para saúde do trabalhador do ponto de vista ergonômico, sendo necessária a modificação das condições de levantamento da carga.

\subsection{Questionário de Queixas Dolorosas e Diagrama de Corllet}

Quanto a sintomatologia de dores e incômodos sentidos operador referiu sintomas nos ombros, quadril / nádegas e pernas / pé nos últimos 30 dias. As pernas e os pés foram citados como região do corpo que mais incomoda durante o horário de trabalho.

O Diagrama das áreas dolorosas criado por Corlett e Manenica (1980). A ferramenta consiste em um diagrama que apresenta o corpo humano dividido em 25 segmentos para que o trabalhador localize as áreas dolorosas com mais facilidade (IIDA, 2005). O trabalhador indica o grau de desconforto através de uma classificação em 5 níveis que varia de 'nenhuma dor' para 'dor insuportável'. Foi orientado que o funcionário respondesse ao questionário preferencialmente no meio da semana, quarta-feira, e em três horários distintos da jornada: Ao chegar ao trabalho; no início do intervalo do almoço; e, ao término do expediente.

Das 25 áreas abrangidas pelo mapa postural, o funcionário pontuou queixas em 6 dessas. Sendo que no início do expediente não há queixas em nenhuma delas. O mesmo pontuou os pés, direito e esquerdo, como áreas de 'dor moderada', e como 'alguma dor' as áreas da nuca, quadril e nádegas.

\section{ANÁLISE DOS RESULTADOS E SUGESTÕES DE MELHORIA}

A partir dos resultados é possível fazer as seguintes considerações:

- O ortostatismo é prolongado:

Os resultados do questionário e do diagrama de desconforto postural condizem com a predominância da postura em pé durante a execução da tarefa, bem como, adoção de posturas inadequadas por conta de um posto de trabalho mal dimensionado e organizado, 


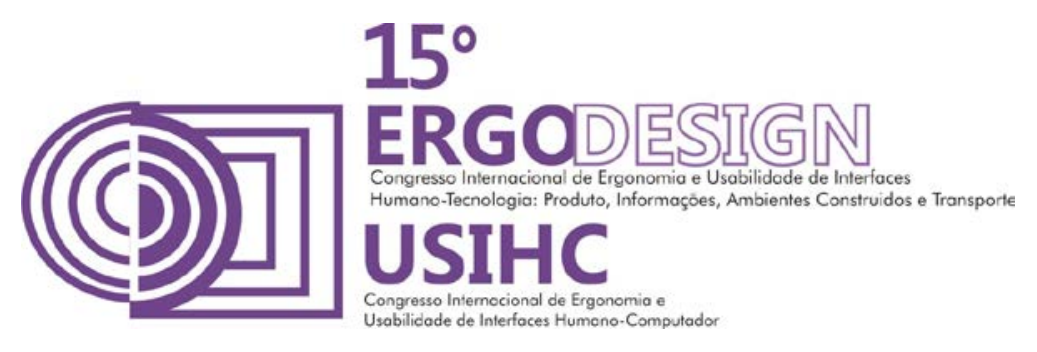

situação que penaliza o trabalhador, o qual refere como principais locais de dor frequentes as pernas e pés.

Segundo a NR-17 justifica-se a adoção da postura em pé, apenas em algumas condições, uma delas é "quando a tarefa exige operações frequentes em vários locais de trabalho, fisicamente separados", no entanto, a mesma norma também preconiza que se o trabalho puder ser executado na posição sentada, o posto de trabalho deverá ser planejado ou adaptado para tal.

Para essa situação recomenda-se a colocação de cadeiras em locais específicos para que seja possível o operador descansar, o que já consta na Consolidação das leis do Trabalho.

- A Carga está acima do ideal e há risco de lombalgias:

De acordo com aplicação da equação de NIOSH (1994), a carga deslocada pelo operador está aproximadamente $5 \mathrm{~kg}$ acima do recomendado enquadrando-se no nível de aumento moderado do risco para o desenvolvimento de lombalgia. Além disso, posturas extremas foram observadas, principalmente relacionadas ao fato das peças serem elevadas a partir do solo, provocando a flexão anterior do tronco.

Estudos realizados por Nachensom (apud KNOPLICH, 1984) demonstram que as inclinações do tronco para frente na postura em pé leva a um aumento de $50 \%$ na pressão intervertebral a nível do $3^{\circ}$ disco lombar.

Nesse ponto, recomenda-se a aquisição de um elevador portátil em tesoura, com altura suficiente para que a carga não seja mais deslocada entre os andares e também que fique próximo a área da preparação das peças no primeiro andar e área de descarga próxima ao setor de montagem no térreo. Para o deslocamento das peças entre o estoque e a área de preparação da peça, sugere-se a aquisição de carros de transporte.

- O layout maximiza os problemas citados:

Verificou-se, a partir da observação e análise da tarefa, que o layout não atende a cinco dos seis princípios básicos propostos por Olivério (1985), da seguinte forma: 1. Princípio da Integração Geral - processos fragmentados em Pavimentos diferentes; 2. Princípio da Mínima Distância de Movimentação - 200m/ciclo (30 canecas); 3. Princípio do Fluxo - muitos cruzamentos, sem sequencias lógicas; 4. Princípio do Espaço Cúbico - espaços inutilizados devido à estocagem; 5. Princípio da Satisfação e Segurança - excesso de deslocamento.

A análise do layout, a partir desses princípios e do registro do fluxo dos processos, foi possível observar que os problemas: posturais e operacionais (deslocamentos excessivos, de frequência do levantamento de carga) deviam-se principalmente ao inadequado arranjo físico. Segundo Costa (2008) um arranjo físico mal projetado ocasiona fluxos excessivamente longos e confusos (de materiais, de informações ou de pessoas), estocagem desnecessária de materiais, e, consequentemente, um aumento nos custos da organização, e por que não dizer, dos custos humanos.

Como solução proposta para o layout atual (Figura $05 \mathrm{~A}$ ), e partir da aplicação do Diagrama de afinidades e análise do fluxo, o processo pode ser organizado em linha, seguindo uma sequência racional de produção conforme (Figura 05 B): 

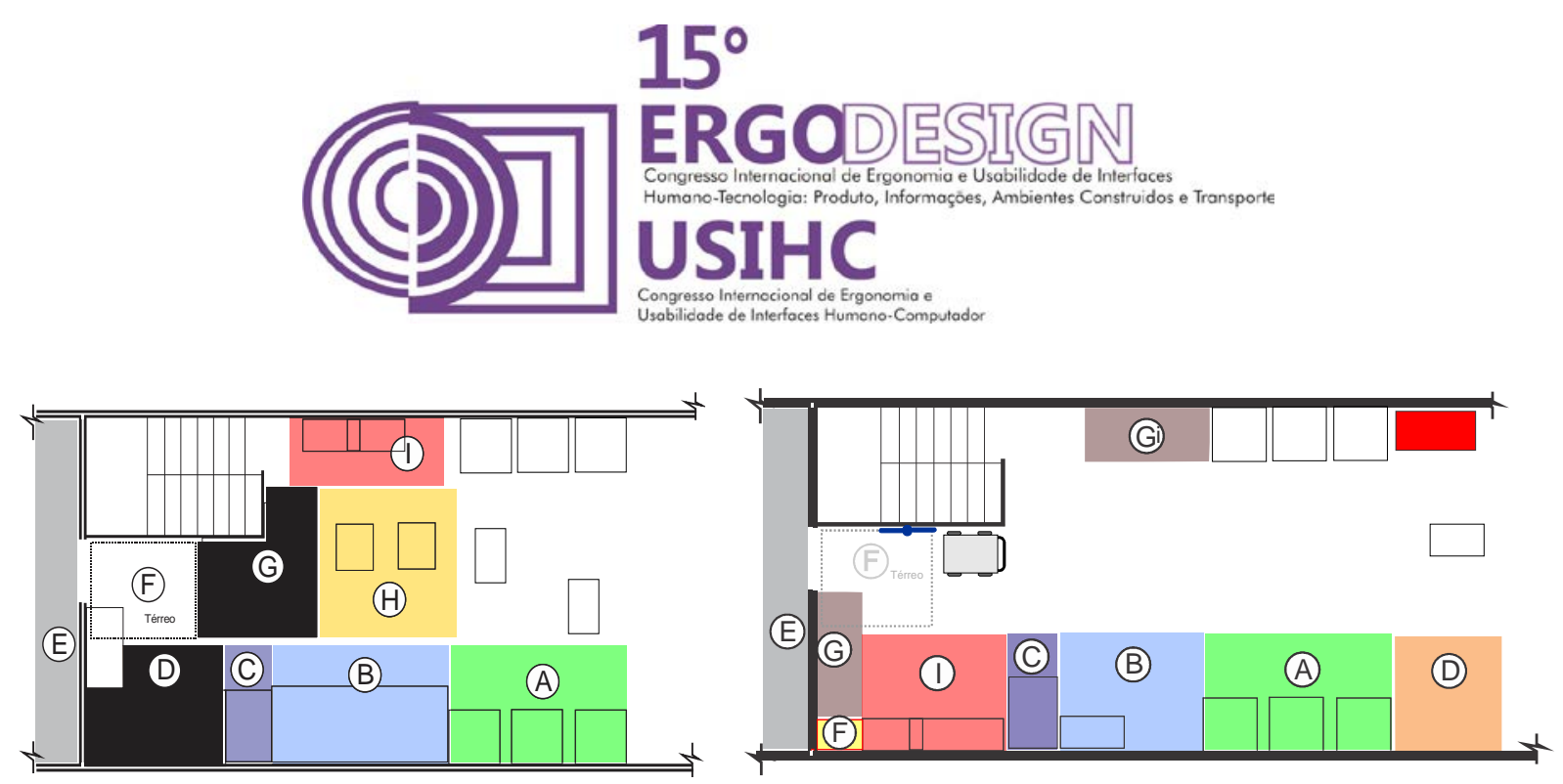

Legenda - A - Estoque 1; B -Área de retirada das canecas dos sacos; C - Máquina de jatear; D - Canecas danificadas; E- Compressor; F - Posto 02 (térreo); G - Estoque 2 de canecas; H - Canecas jateadas; I - Bancada de Perfuração

Figura 05- (A) Layout atual

(B) Proposta de novo layout

Com esta proposta, as ações e os deslocamentos realizados são reduzidos, bem como, o esforço físico para deslocamento das cargas, pois os estoques estão próximos da área de trabalho. O layout proposto considera o uso do elevador de carga $(F)$ e utilização de carros de transporte. O Quadro 07, resume as mudanças para um ciclo de produção de 30 canecas.

Quadro 07 - Demonstrativo das mudanças operacionais a partir do layout proposto.

\begin{tabular}{|c|c|c|c|c|c|c|c|c|}
\hline \multicolumn{2}{|c|}{ Qtde de Operações } & \multicolumn{2}{|c|}{ Deslocamentos } & Tempo Espera & \multicolumn{2}{c|}{$N^{\circ}$ de Estoque } & \multicolumn{2}{c|}{ Inspeção } \\
\hline Layout & Layout & Layout & Layout & Layout atual e & Layout & Layout & Layout & Layout \\
atual & proposto & atual & proposto & proposto: & atual & proposto & atual & proposto \\
10 & 09 & 45 & 02 & Variável & 02 & 02 & 01 & 01 \\
& & $(200 \mathrm{~m})$ & $(20 \mathrm{~m})$ & & & & \\
\hline
\end{tabular}

\section{CONSIDERAÇOES FINAIS}

O presente estudo apresentou parte da análise ergonômica do posto de trabalho de um operador de montagem em uma indústria de produção de bombas submersas, demonstrando, em sua fase exploratória, problemas flagrantes em relação às más posturas e ao levantamento e carregamento frequente de carga, os quais foram selecionados como objeto de análise na fase de diagnose.

O diagnóstico corroborou para a evidenciação das condições inadequadas de levantamento de carga e seus custos ao trabalho por meio da aplicação da equação NIOSH (1994) e questionário de queixas dolorosas, e adicionalmente para problemas relacionados ao arranjo físico do posto de trabalho.

Nesse sentido, a metodologia aplicada, bem como os instrumentos adotados, mostraram-se eficazes para uma análise com enfoque sistêmico. Proporcionando assim, um diagnóstico e proposição de melhorias de forma mais assertiva, através de soluções não apenas pontuais mas também de forma ampla a fim de reorganizar todo o sistema da Unidade produtiva analisada.

8. REFERÊNCIAS BIBLIOGRÁFICAS

BARREIRA, T. H. C. Um enfoque Ergonômico para as Posturas de Trabalho. Revista Brasileira de Saúde Ocupacional. São Paulo, n. 17, v. 67, 1989. 


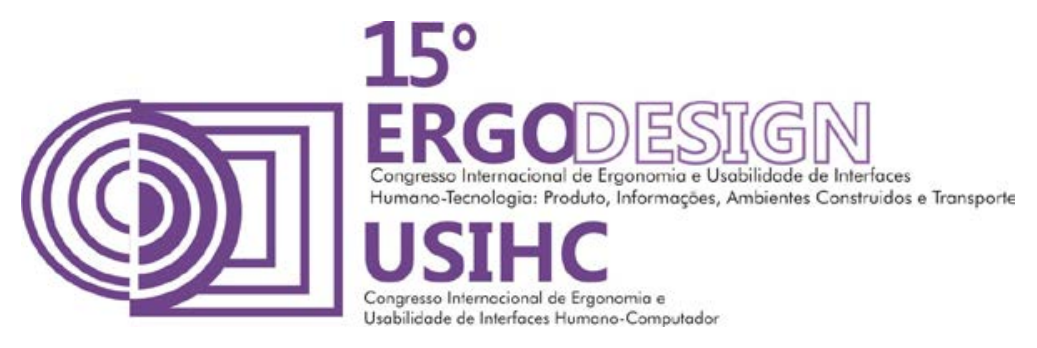

BRASIL. Ministério do Trabalho e Emprego. Manual de aplicação da Norma Regulamentadora ${ }^{\circ}$ 17. 2 ed. Brasília, 2002

BRASIL. Ministério do Trabalho e Emprego. Nota Técnica 060/2001. Ergonomia - indicação de postura a ser adotada na concepção de postos de trabalho. Secretaria de Inspeção do Trabalho. Departamento de Segurança e Saúde no Trabalho. Coordenação de Normatização.Disponívelem:<http://www3.mte.gov.br/seg_sau/comissoes_cne_notatecnica.pdf>. Acesso em: Julho de 2014.

BRASIL. Ministério da Previdência Social. Anuário Estatístico da Previdência Social - ano 2012. Brasília, 2012. Disponível em:< http://www.previdencia.gov.br/estatisticas/: acesso em: 08.mai.2014

COSTA, J.H.S. Análise do Trabalho e Estudo ergonômico para mudança de arranjo físico.2008. Monografia (Graduação de Engenharia da Produção) - Escola Politécnica da Universidade de São Paulo. São Paulo, 2008.

IIDA, Itiro. Ergonomia projeto e produção. 5.ed. São Paulo: Edgard Blücher. 2005.

$\mathrm{KNOPLICH}, \mathrm{J}$. Viva bem com a coluna que você tem: dores nas costas, tratamento e prevenção. 10ª ed. São Paulo: Ibrasa, 1984.

MORAES, A. \& MONT'ALVÃO, C. Ergonomia: conceitos e aplicações. 4 ed. Rio de Janeiro: 2AB, 2010.

OLIVÉRIO, José Luiz. Projeto de Fábrica: produtos processos e instalações industriais. São Paulo: IBLC, 1985.

WATERS, Thomas R. et al. Applications manual for the revised NIOSH lifting equation. National Institute for Occupational Safety and Health (NIOSH). Publication no 94-110. Cincinnati /Ohio, january, 1994. 